\title{
STUDI PEREMAJAAN TANAMAN KELAPA SAWIT DI AREAL LAHAN TANAH MINERAL DAN LAHAN GAMBUT
}

\section{STUDY ON REPLANTING OF PALM OIL PLANTS IN MINERAL LAND AND PEAT LAND AREAS}

\author{
Gatot Pramuhadi ${ }^{1 凶}$, Muhammad Aji Setiawan², Nenda Fuji Putri Daliesta ${ }^{2}$ \\ ${ }^{1}$ Departemen Teknik Mesin dan Biosistem, Institut Pertanian Bogor \\ ${ }^{2}$ Program Studi Teknologi dan Manajemen Produksi Perkebunan, Institut Pertanian Bogor \\ ${ }^{\circledR}$ Komunikasi Penulis, email: gph3025818@gmail.com \\ DOI:http://dx.doi.org/10.23960/jtep-lv9i3.201-212
}

Naskah ini diterima pada 12 April 2020; revisi pada 27 Agustus 2020;

disetujui untuk dipublikasikan pada 30 Agustus 2020

\begin{abstract}
Oil palm trees that are more than 25 years old generally have low productivity of oil palm fruit and will decrease in productivity. For this reason, it is necessary to replant oil palm plants so that their productivity can be maintained high and increased. The aim of this research is to study the technique of replanting oil palm plants in mineral soil areas in the area of Kebun Aek Loba, PT Socfindo, Asahan Regency, North Sumatra Province and in the peatland area of Kebun Mandah Estate, PT Bhumireksa Nusa Sejati, Riau Province. Soil types in the Aek Loba garden area were dominated by mineral soils of the typic hapludult class and made from mother rock tufo toba and young alluvium with a soil pH of 5.5. Mandah Estate plantation area is $100 \%$ peat soil with a composition of $74 \%$ mature peat (sapric) and 26\% medium peat (hemic). Peat is more than 3 meters deep (including very deep peat) and has a crumbly texture so it is easy to erode. The peat soil includes ombrogin peat (formed from large swampy plains), has a high acid content with a $\mathrm{pH}<5.5$, and has a peat soil density of $(1.25-1.80) \mathrm{g} / \mathrm{cc}$. Replanting activities in mineral soil areas include ripping, plowing, chipping, holing to planting with a large field capacity (0.04-0.72) ha / hour and a total time of completion of work (total field time) of 139.5 hours / ha. Replanting activities in peatland areas include falling, chipping, deboling, holing and planting with a large field capacity $(0.06-1.25)$ ha / hour and a total field time of 73.7 hours / ha.
\end{abstract}

Keywords: field capacity, mineral soils, peatlands, replanting, total field time

\begin{abstract}
ABSTRAK
Tanaman (pohon) kelapa sawit yang telah berumur lebih dari 25 tahun umumnya memiliki produktivitas buah kelapa sawit yang rendah dan akan semakin menurun produktivitasnya. Untuk itu perlu dilakukan penanaman kembali/peremajaan (replanting) tanaman kelapa sawit agar produktivitasnya bisa dipertahankan terjaga tinggi dan meningkat. Tujuan penelitian yaitu mempelajari teknik proses peremajaan (replanting) tanaman kelapa sawit di areal lahan tanah mineral di areal Kebun Aek Loba, PT Socfindo, Kabupaten Asahan, Provinsi Sumatera Utara dan di areal lahan gambut Kebun Mandah Estate, PT Bhumireksa Nusa Sejati, Provinsi Riau. Jenis tanah di areal Kebun Aek Loba didominansi oleh tanah mineral dari kelas typic hapludult dan berbahan induk batuan tufo toba dan aluvium muda dengan $\mathrm{pH}$ tanah 5.5. Areal kebun Mandah Estate $100 \%$ merupakan tanah gambut dengan komposisi gambut matang (saprik) 74\% dan gambut sedang (hemik) 26\%. Kedalaman gambut lebih dari 3 meter (termasuk gambut sangat dalam) dan memiliki tekstur remah sehingga mudah terjadi erosi. Tanah gambutnya termasuk gambut ombrogin (terbentuk dari dataran rawa luas), memiliki kadar asam tinggi dengan $\mathrm{pH}<5.5$, dan memiliki densitas tanah gambut sebesar $(1.25-1.80) \mathrm{g} / \mathrm{cc}$. Kegiatan replanting di areal lahan tanah mineral meliputi pekerjaan ripping, plowing, chipping, holing hingga penanaman dengan besar kapasitas lapang (0.04 0.72 ) ha/jam dan besar total waktu penyelesaian pekerjaan (waktu lapang total) sebesar $139.5 \mathrm{jam} / \mathrm{ha}$. Kegiatan replanting di areal lahan gambut meliputi pekerjaan falling, chipping, deboling, holing hingga penanaman dengan besar kapasitas lapang $(0.06-1.25) \mathrm{ha} / \mathrm{jam}$ dan besar waktu lapang total $73.7 \mathrm{jam} / \mathrm{ha}$.
\end{abstract}

Kata kunci: kapasitas lapang, lahan gambut, replanting, tanah mineral, waktu lapang total 


\section{PENDAHULUAN}

Kelapa sawit (Elaeis Guineensis Jacq.) masih menjadi andalan Indonesia sebagai komoditas ekspor maupun untuk memenuhi kebutuhan dalam negeri yang dari tahun ke tahun semakin meningkat (Siswadi 2016). Kelapa sawit merupakan penghasil minyak nabati yang paling efisien karena dapat menghasilkan 5-8.4 ton minyak/ha, sedangkan kedelai, yang merupakan saingan utama, hanya mampu menghasilkan 0.4 ton minyak/ha. Saat ini berkisar 70 negara menggunakan minyak sawit sebagai bahan baku industri pangan maupun non-pangan (Risza, 1994). Prospek pasaran dunia untuk minyak kelapa sawit dan produk-produknya cukup bagus sehingga perkebunan kelapa sawit sekarang telah diperluas secara besar-besaran. Ekspansi areal kebun dilakukan oleh perkebunan negara, perkebunan besar swasta hingga perkebunan rakyat (Sunarko 2014).

Berdasarkan data dari BPS (2017) disebutkan bahwa produksi kelapa sawit di Indonesia pada tahun 2011 hingga tahun 2015 telah mengalami peningkatan, yaitu sebesar $22,496,900$ ton, $26,015,520$ ton, $27,782,000$ ton, $29,278,200$ ton, dan 31,284,300 ton. Data tersebut menunjukkan bahwa produksi kelapa sawit di Indonesia mengalami peningkatan yang cukup stabil setiap tahunnya. Peningkatan tersebut disebabkan oleh penambahan luas areal perkebunan kelapa sawit setiap tahunnya, serta pengelolaan perkebunan kelapa sawit yang semakin intensif.

Badan Pengelola Dana Perkebunan (BPDP) mencatat luas areal kelapa sawit \pm 11.26 juta hektar pada tahun 2015 dengan jumlah tanaman tidak menghasilkan (TTM) dan tanaman rusak (TR) \pm 206501 pada tahun 2015 hingga tahun 2017 (BPDP Sawit 2017). Peremajaan sebagai salah satu tindakan manajemen untuk mempertahankan rata-rata umur tanaman tetap optimal bagi perusahaan (Pahan, 2008). Peremajaan adalah pembukaan areal dari bekas perkebunan kelapa sawit yang sudah tua dan tidak produktif lagi (Fauzi et al,2012). Batas umur tanaman produktif sesuai nilai ekonomi berkisar antara 25 tahun hingga 27 tahun dengan produksi \pm 14 ton/ha/tahun (Pahan 2008) . Umur ekonomis tanaman kelapa sawit adalah 25 tahun karena produktivitas tanaman kelapa sawitnya sudah kurang dari 15 ton/ha. Produktivitas tersebut dinilai tidak memiliki nilai ekonomis sehingga perlu dilakukan peremajaan. Peremajaan kelapa sawit merupakan kegiatan mengganti tanaman kelapa sawit yang sudah tua (tidak memiliki nilai ekonomis) dengan bibit atau tanaman kelapa sawit yang baru.

Di Indonesia banyak areal perkebunan kelapa sawit yang tersebar pada lahan-lahan marginal maupun lahan-lahan produktif, baik pada lahan tanah mineral maupun pada lahan gambut. Kondisi media tanam yang berbeda tentunya akan memberikan gambaran yang berbeda pula pada saat dilakukan kegiatan peremajaan tanaman (replanting) kelapa sawit. Dengan demikian bisa dilakukan kajian (studi) guna menelaah (mempelajari) perbedaan metode dan kinerja kegiatan proses replanting di areal lahan tanah mineral dan lahan gambut.

\section{BAHAN DAN METODA}

Kajian (studi) kegiatan replanting di areal lahan tanah mineral dan lahan gambut dilaksanakan secara serentak mulai tanggal 05 Februari 2018 hingga 05 Mei 2018, yaitu di areal Kebun Aek Loba, PT Socfindo, Kabupaten Asahan, Provinsi Sumatera Utara dan di areal lahan gambut Mandah Estate, PT Bhumireksa Nusa Sejati, Desa Bente, Kecamatan Mandah, Kabupaten Indragiri Hilir, Provinsi Riau. Adapun data primer (data waktu operasional dan kinerja atau kapasitas lapang setiap kegiatan) dan data sekunder (deskripsi, urutan, dan metode setiap kegiatan) yang dikumpulkan terutama digunakan untuk menetapkan teknik kegiatan peremajaan tanaman kelapa sawit dan menganalisis kinerja setiap kegiatan mulai dari kegiatan persiapan hingga kegiatan penanaman.

Pada setiap proses kegiatan replanting dilakukan pengukuran kinerja aktual di lapangan dan dianalisis untuk menetapkan besar kapasitas lapang (ha/jam) dan waktu lapang (jam/ha) setiap kegiatan. Selanjutnya, dihitung besar total waktu yang dibutuhkan untuk menyelesaikan serangkaian kegiatan replanting (jam/ha), baik di areal lahan tanah mineral maupun di areal lahan gambut. 


\section{HASIL DAN PEMBAHASAN}

Keadaan tanah di Kebun Aek Loba memiliki drainase yang baik sampai ke lapisan bawah dengan adanya kuarsa merah kekuningan dan memiliki tekstur tanah lempung liat berpasir. Topografi Kebun Aek Loba terdiri atas area dengan slope datar (0-4)\% sebanyak $45 \%$ areal, $50 \%$ areal bergelombang (4-12) $\%$, dan $5 \%$ areal berbukit (12-24)\%. Tanah di Kebun Aek Loba didominansi oleh tanah mineral dari kelas typic hapludult dan berbahan induk batuan tufo toba dan aluvium muda dengan $\mathrm{pH}$ tanah 5.5. Areal kebun Mandah Estate 100\% merupakan tanah gambut dengan komposisi gambut matang (saprik) 74\% dan gambut sedang (hemik) 26\%. Kedalaman gambut lebih dari 3 meter (termasuk gambut sangat dalam) dan memiliki tekstur remah sehingga mudah terjadi erosi. Tanah gambutnya termasuk gambut ombrogin (terbentuk dari dataran rawa luas), memiliki kadar asam tinggi dengan $\mathrm{pH}<5.5$, dan memiliki densitas tanah gambut sebesar $(1.25-1.80) \mathrm{g} /$ cc.

Di areal lahan tanah mineral Kebun Aek Loba, kegiatan-kegiatan yang dilaksanakan sebelum kegiatan proses replanting terdiri atas kegiatan : (1) ripping, (2) plowing, (3) pemancangan rumpukan, (4) tumbang dan chipping, (5) perbaikan drainase, (6) pemancangan tanaman, (7) stek tanaman kacangan, (8) penanaman kacangan, (9) holing, dan (10) rawat kacangan. Kegiatan-kegiatan yang dilaksanakan sebelum kegiatan replanting di areal lahan gambut Kebun Mandah Estate meliputi kegiatan : (1) falling, chipping, dan deboling, (2) pembuatan CECT, (3) pembuatan field drain, (4) pembuatan $K C B$, (5) pembuatan central drain, (6) cambering, (7) compacting, (8) pemancangan, (9) holing, dan (10) penanaman LCC. Pada Tabel 1 ditunjukkan deskripsi setiap kegiatan sebelum dan saat dilakukan replanting tanaman kelapa sawit.

\subsection{Peremajaan Kelapa Sawit di Areal Lahan Tanah Mineral}

Umur ekonomis pohon sawit di areal Kebun Aek Loba yaitu 25 tahun, dimana produktivitasnya kurang dari 15 ton/ha. Produktivitas pohon kelapa sawit tersebut dinilai tidak memiliki nilai ekonomis sehingga perlu dilakukan peremajaan (replanting). Kegiatan ripping bertujuan untuk memecah lapisan tanah bagian dalam agar aerasi lebih baik, pengendalian populasi gulma, pengolahan tanah untuk LCC, perataan tanah, dan pemecahan lapisan tanah atas sehingga memudahkan pengolahan tanah selanjutnya. Waktu operasional kegiatan ripping sebesar 8 jam perhari, besar kapasitas lapang $0.25 \mathrm{ha} / \mathrm{jam}$, dan waktu lapang 4.0 jam/ha. Dalam Gambar 1 ditunjukkan contoh kegiatan ripping di areal lahan tanah mineral.

Kegiatan plowing (ploughing) dilakukan setelah ripping menggunakan bajak piring 3 bottom berdiameter $70 \mathrm{~cm}$ dan jarak antar piring $64 \mathrm{~cm}$ yang ditarik oleh traktor roda empat, sebagaimana ditunjukkan dalam Gambar 2 . Waktu operasional kegiatan plowing sebesar 8 jam perhari, besar kapasitas lapang $0.25 \mathrm{ha} / \mathrm{jam}$, dan waktu lapang 4.0 jam/ha. Adapun arah ripping dan plowing ditunjukkan dalam Gambar 3.

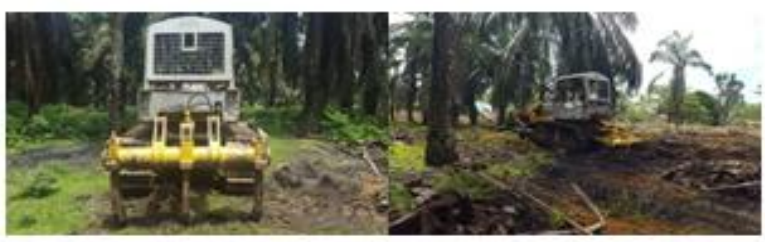

Gambar 1. Kegiatan Ripping di Lahan Tanah Mineral

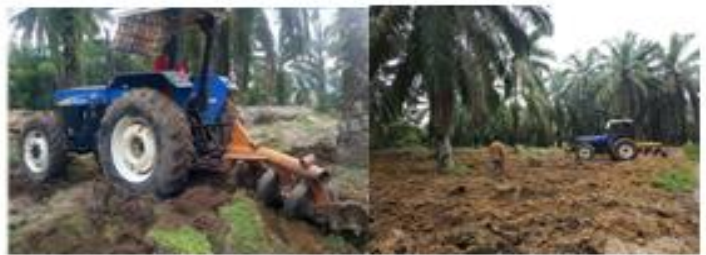

Gambar 2. Kegiatan Plowing di Lahan Tanah Mineral 
Tabel 1. Deskripsi Beberapa Kegiatan Sebelum dan Saat Dilakukan Replanting Tanaman Kelapa Sawit

\begin{tabular}{|c|c|}
\hline Kegiatan & Deskripsi \\
\hline Ripping & $\begin{array}{l}\text { Proses pemecahan lapisan tanah dengan kedalaman }(60-65) \mathrm{cm} \text { memotong barisan } \\
\text { tanaman menggunakan bulldozer dan implemen ripper }\end{array}$ \\
\hline Plowing / ploughing & $\begin{array}{l}\text { Kegiatan memotong dan membalik tanah pada kedalaman (23-28) } \mathrm{cm} \\
\text { menggunakan traktor roda empat dan implemen bajak piring (disk plow) }\end{array}$ \\
\hline Falling & $\begin{array}{l}\text { Kegiatan merobohkan/menumbangkan pohon sawit secara mekanis menggunakan } \\
\text { mesin excavator untuk memudahkan pekerjaan chipping }\end{array}$ \\
\hline Chipping & $\begin{array}{l}\text { Kegiatan mencacah/mencincang pohon sawit yang ditumbangkan (hasil pekerjaan } \\
\text { falling)menggunakan mesin excavator }\end{array}$ \\
\hline Deboling & $\begin{array}{l}\text { Kegiatan pembongkaran bonggol perakaran pohon sawit yang bertujuan untuk } \\
\text { memutus siklus hidup jamur ganoderma }\end{array}$ \\
\hline Holing & Kegiatan pembuatan lubang tanam untuk penanaman bibit kelapa sawit \\
\hline Cambering & $\begin{array}{l}\text { Kegiatan pengolahan tanah dengan cara menumpuk dan meratakan tanah hasil } \\
\text { galian CECT dan field drain untuk membuat jalur tanam berbentuk cembung serta } \\
\text { membersihkan lahan dari serasah tanaman lama }\end{array}$ \\
\hline Compacting & $\begin{array}{l}\text { Kegiatan pemadatan jalur tanam sehingga tanaman dapat tumbuh dengan baik dan } \\
\text { lebih kokoh }\end{array}$ \\
\hline Pemancangan rumpukan & $\begin{array}{l}\text { Kegiatan menentukan rintisan dan gawangan pada tanaman baru sehingga lubang } \\
\text { tanam tidak berada pada rumpukan }\end{array}$ \\
\hline $\begin{array}{l}\text { Pembuatan CECT (close } \\
\text { ended conservation } \\
\text { trenches) }\end{array}$ & $\begin{array}{l}\text { Kegiatan pembuatan parit konservasi dengan ujung tertutup yang berfungsi sebagai } \\
\text { tempat penampung hasil chipping untuk meminimalkan perkembangan kumbang } \\
\text { tanduk dan sekaligus menutup lubang hasil deboling }\end{array}$ \\
\hline Perbaikan drainase & Kegiatan untuk memperbaiki parit primer, parit sekunder, dan alur \\
\hline Pembuatan field drain & $\begin{array}{l}\text { Kegiatan membuat parit sebagai tempat aliran air agar lahan tidak tergenang serta } \\
\text { berfungsi sebagai kantung persediaan air ketika musim kemarau }\end{array}$ \\
\hline Pembuatan central drain & $\begin{array}{l}\text { Kegiatan membuat parit untuk menghubungkan field drain dengan kanal kolektor, } \\
\text { yang dilakukan ketika proses penanaman telah selesai untuk mempercepat dan } \\
\text { mempermudah proses pelangsiran bibit pada saat proses penanaman }\end{array}$ \\
\hline $\begin{array}{l}\text { Pembuatan KCB (kanal } \\
\text { cabang baru) }\end{array}$ & $\begin{array}{l}\text { Kegiatan membuat kanal sebagai sarana transportasi untuk mempercepat dan } \\
\text { mempermudah proses langsir bibit, langsir pupuk, dan evakuasi TBS }\end{array}$ \\
\hline Pemancangan tanaman & $\begin{array}{l}\text { Kegiatan pemasangan pancang-pancang untuk mendapatkan barisan tanaman yang } \\
\text { sejajar atau beraturan }\end{array}$ \\
\hline Stek tanaman kacangan & $\begin{array}{l}\text { Stek yang berasal dari areal tanaman kacangan yang ditanam pada areal tanaman } \\
\text { kelapa sawit berumur } 1 \text { tahun }\end{array}$ \\
\hline $\begin{array}{l}\text { Penanaman LCC (legume } \\
\text { cover crop) }\end{array}$ & $\begin{array}{l}\text { Kegiatan menanam tanaman kacangan atau legume cover crop (LCC), yaitu Mucuna } \\
\text { bracteata }\end{array}$ \\
\hline
\end{tabular}

Pemancangan rumpukan dilakukan sebelum penumbangan pohon. Pemancangan rumpukan dilakukan untuk menentukan rintis dan gawangan pada tanaman baru sehingga lubang tanam tidak berada pada rumpukan. Tinggi pancang rumpukan sebesar $\pm 2.5 \mathrm{~m}$ dan diberi plastik putih di atasnya, sebagaimana pola pemancangan rumpukannya ditunjukkan dalam Gambar 4. Waktu operasional kegiatan pemancangan rumpukan sebesar 7 jam perhari, besar kapasitas lapang 0.57 ha/jam, dan waktu lapang $1.7 \mathrm{jam} / \mathrm{ha}$.

Penumbangan/falling yaitu kegiatan merobohkan tanaman kelapa sawit secara mekanis menggunakan excavator.Arah penumbangan yaitu timur ke barat agar pohon sawit yang telah tumbang tidak melintang pada rintis maupun parit. Proses perumpukan setelah chipping juga lebih mudah dan tidak memakan 


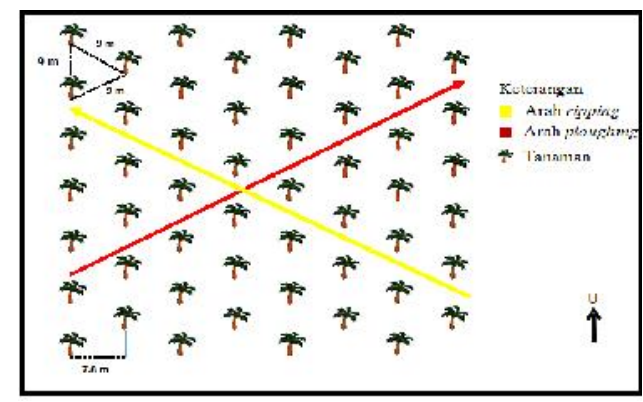

Gambar 3. Arah Ripping dan Plowing (Ploughing)

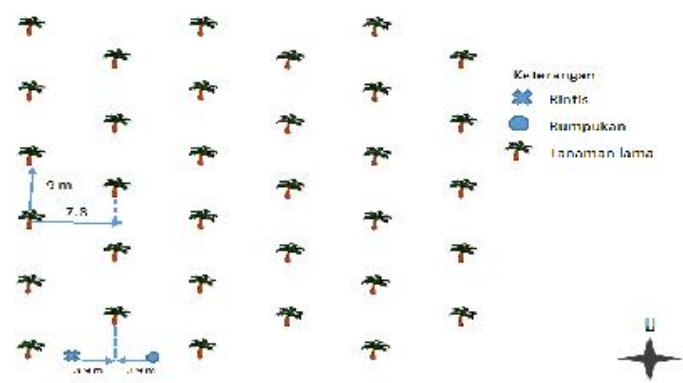

Gambar 4. Pola Pemancangan Rumpukan

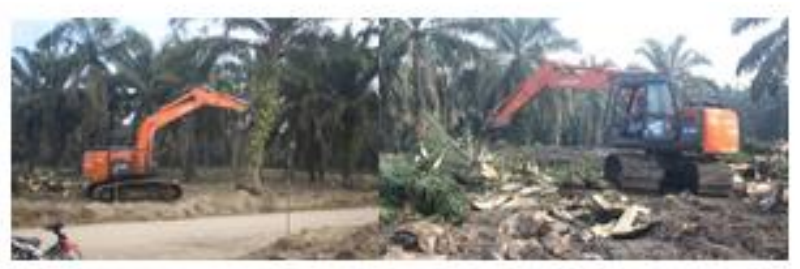

Gambar 5. Kegiatan Falling dan Chipping di Tanah Mineral

waktu yang lama untuk merumpuk. Pohon yang telah tumbang kemudian dicacah menjadi beberapa irisan atau chipping. Kapasitas lapang kegiatan tumbang dan chipping dipengaruhi oleh kondisi pohon kelapa sawit, semakin tinggi pohon maka kapasitas lapang semakin rendah. Topografi areal replanting juga berpengaruh terhadap kapasitas lapang, semakin berbukit areal tersebut maka ouput semakin rendah karena ruang gerak excavator yang berat. Waktu operasional kegiatan falling dan chipping sebesar 10 jam perhari, besar kapasitas lapang $0.05 \mathrm{ha} /$ jam, dan waktu lapang 20.0 jam/ha. Dalam Gambar 5 ditunjukkan contoh kegiatan falling dan chipping di areal lahan tanah mineral.

Desain blok atau areal peremajaan mengikuti desain sebelumnya sehingga perbaikan jalan dan drainase (out let, alur, parit sekunder dan primer) mengikuti alur sebelumnya. Pembuatan saluran drainase baru perlu dilakukan apabila areal peremajaan tersebut merupakan areal rendahan dan berpotensi terjadi genangan air pada areal tersebut. Pembuatan jalan kebun baru dilakukan apabila areal peremajaan memiliki jalur transportasi yang sulit sehingga perlu dibuat jalan baru. Waktu operasional perbaikan/ pembuatan parit primer, parit sekunder, dan alur berturut-turut masing-masing sebesar 8 jam perhari, besar kapasitas lapangnya $0.72 \mathrm{ha} / \mathrm{jam}$, 0.52 hajam, dan $0.23 \mathrm{ha} /$ jam dengan waktu lapangnya sebesar 1.4 jam/ha, 1.9 jam/ha, dan $4.3 \mathrm{jam} / \mathrm{ha}$.

Pemancangan bertujuan mendapatkan barisan tanaman yang sejajar/beraturan. Pemancangan tanaman kacangan (LCC) bersamaan pemancangan tanaman kelapa sawit agar lebih efisien. Jarak tanam $9 \mathrm{~m} \times 9 \mathrm{~m} \times 9 \mathrm{~m}$ (membentuk segitiga sama sisi) arah utara ke selatan dan jarak antar barisan $7.8 \mathrm{~m}$ arah barat ke timur sehingga diperoleh populasi 143 pohon/ha. Waktu operasional kegiatan pemancangan tanaman sebesar 7 jam perhari, besar kapasitas lapang $0.04 \mathrm{ha} / \mathrm{jam}$, dan waktu lapang $25.0 \mathrm{jam} / \mathrm{ha}$. Dalam Gambar 6 ditunjukkan pola pemancangan. 
Holing merupakan kegiatan pembuatan lubang tanam bibit sawit secara mekanis menggunakan traktor roda empat dan implemen holedigger. Ukuran lubang tanam memiliki diameter $60 \mathrm{~cm}$ dan kedalaman $60 \mathrm{~cm}$. Berdasarkan hasil pengukuran di lapangan diperoleh rata-rata diameter lubang $64.5 \mathrm{~cm}$ dan kedalaman $62.4 \mathrm{~cm}$. Waktu operasional kegiatan holing sebesar 8 jam perhari, besar kapasitas lapang $0.35 \mathrm{ha} / \mathrm{jam}$, dan waktu lapang 2.9 jam/ha. Dalam Gambar 7 ditunjukkan contoh kegiatan holing di areal lahan tanah mineral.

Penanaman bibit kelapa sawit ke lubang tanam dilakukan secara manual oleh karyawan. Bibit kelapa sawit yang akan ditanam di lahan merupakan bibit normal dan berumur 8-12 bulan. Bibit normal merupakan bibit sehat, tidak terserang hama dan penyakit, serta pertumbuhannya tidak kerdil. Pengangkutan bibit ke lapangan menggunakan truk berkapasitas 150 bibit/truk. Bibit disusun membentuk piramida sebanyak tumpukan. Bibit kemudian dilansir pada setiap rintis sesuai dengan jumlah tanaman pada setiap rintis. Waktu operasional kegiatan penanaman bibit sawit sebesar 6.5 jam perhari, besar kapasitas lapang $0.10 \mathrm{ha} / \mathrm{jam}$, dan waktu lapang $10.0 \mathrm{jam} / \mathrm{ha}$. Kegiatan pengangkutan dan penanaman bibit sawit ditunjukkan dalam Gambar 8.

\subsection{Peremajaan Kelapa Sawit di Areal Lahan Gambut}

Kriteria kebun replanting di Mandah Estateadalah pohon kelapa sawit yang telah berumur 20 tahun lebih, tinggi rata-rata lebih dari $15 \mathrm{~m}$, dan produktivitas kurang dari 20 ton/ha/ tahun selama 3 tahun berturut-turut. Apabila kebun telah memenuhi paling tidak 2 dari 3 kriteria tersebut, maka dapat dipertimbangkan untuk dilakukan peremajaan (replanting).

Kegiatan falling merupakan kegiatan merobohkan pohon sawit sehingga memudahkan proses chipping dan rumpuk di dekat CECT (close ended conservation trenches). Chipping merupakan kegiatan mencacah batang, pelepah, dan bonggol perakaran sawit untuk memudahkan proses dekomposisi. Deboling adalah kegiatan pembongkaran bonggol perakaran yang bertujuan untuk memutus siklus

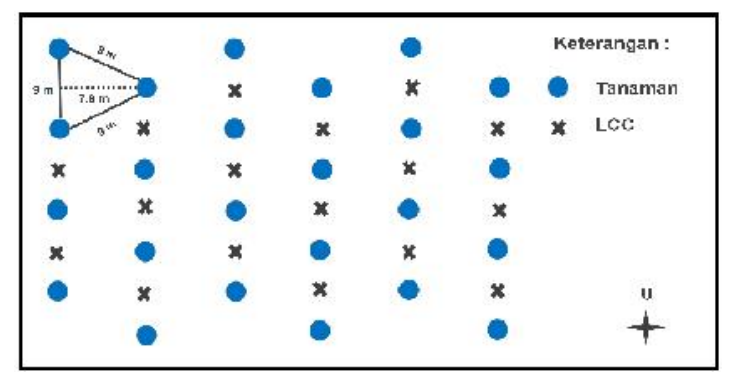

Gambar 6. Pola Pemancangan Tanaman

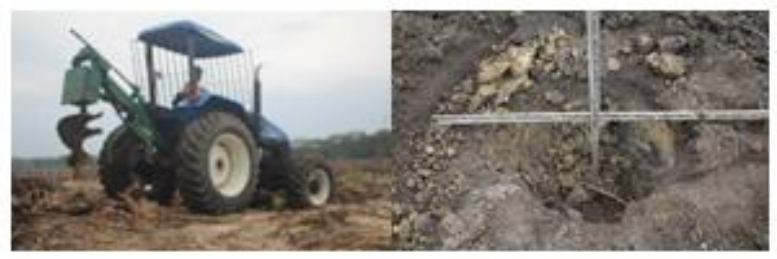

Gambar 7. Kegiatan Holing dan Pengukuran Lubang Tanam

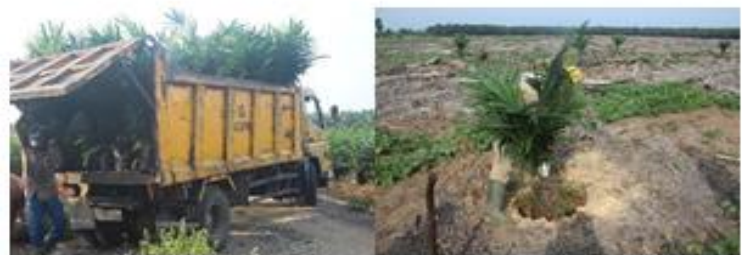

Gambar 8. Pengangkutan dan Penanaman Bibit Sawit 
hidup jamur ganoderma. Kegiatan falling, chipping, dan debolingdilakukan sekaligus agar lebih efektif dan efisien. Waktu operasional kegiatan falling, chipping, dan deboling sebesar 10 jam perhari, besar kapasitas lapang $0.08 \mathrm{ha} /$ jam, dan waktu lapang $12.0 \mathrm{jam} / \mathrm{ha}$. Dalam Gambar 9 ditunjukkan urutan kegiatan falling, chipping, dan deboling.

CECT (parit konservasi dengan ujung tertutup) berfungsi sebagai tempat penampung hasil chipping untuk meminimumkan perkembangbiakan kumbang tanduk. Pembuatan CECT dilakukan sekaligus untuk menutup lubang hasil deboling. Ukuran parit CECT yaitu[panjang, lebar atas, lebar bawah, kedalaman $]=[109.5 \mathrm{~m}, 2.4 \mathrm{~m}, 1.8 \mathrm{~m}, 1.2 \mathrm{~m}]$. Waktu operasional pembuatan CECT sebesar 10 jam perhari, besar kapasitas lapang $0.14 \mathrm{ha} / \mathrm{jam}$, dan waktu lapang 7.14 jam/ha. Dalam Gambar 10 ditunjukkan metode dan hasil akhir pembuatan CECT.

Field drain adalah parit yang terhubung dengan parit central drain. Field drain berfungsi sebagai tempat aliran air agar lahan tidak tergenang serta sebagai kantung persediaan air ketika musim kemarau. Kegiatan pembuatan field drain dilakukan setelah kegiatan falling, chipping, dan deboling selesai. Ukuran parit field drain yaitu[panjang, lebar atas, lebar bawah, kedalaman $]=[115.5 \mathrm{~m}, 1 \mathrm{~m}, 0.8 \mathrm{~m}, 1 \mathrm{~m}]$. Waktu operasional pembuatan field drain sebesar 10 jam perhari, besar kapasitas lapang $0.16 \mathrm{ha} / \mathrm{jam}$, dan waktu lapang $6.25 \mathrm{jam} / \mathrm{ha}$. Hasil pembuatan field drain ditunjukkan dalam Gambar 11.
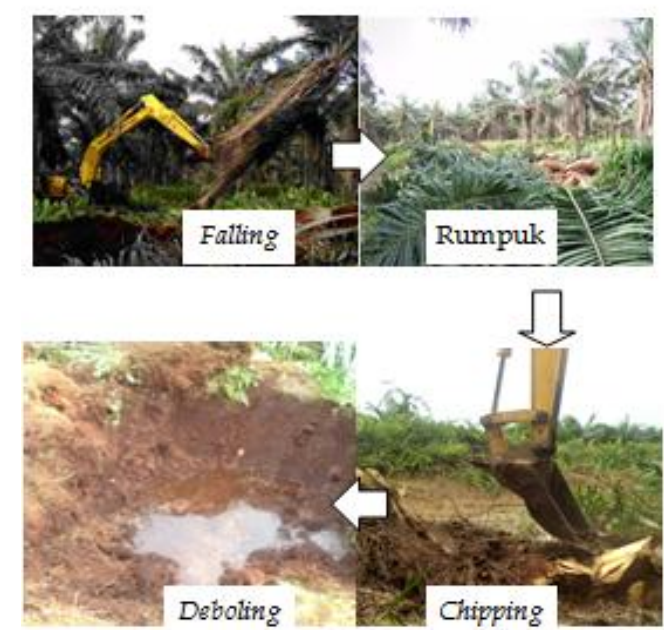

Gambar 9. Urutan Kegiatan Falling, Chipping, dan Deboling

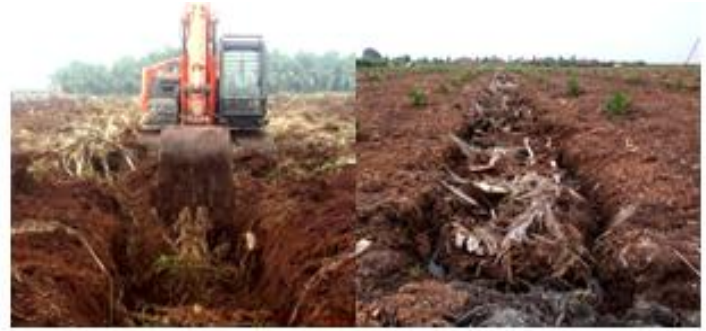

Gambar 10. Metode dan Hasil Akhir Pembuatan CECT

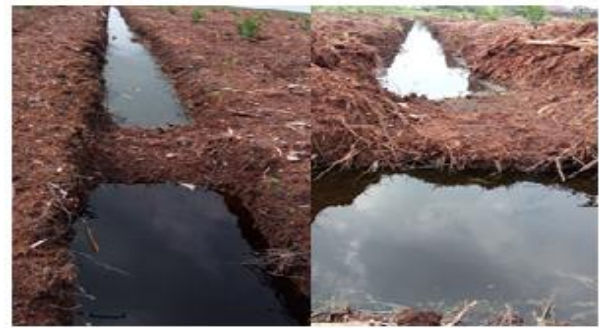

Gambar 11. Hasil Pembuatan Field Drain 
KCB (kanal cabang baru) adalah kanal yang berfungsi sebagai sarana transportasi untuk mempercepat dan mempermudah proses langsir bibit, langsir pupuk, dan evakuasi TBS. KCB dibuat dengan ukuran yaitu[panjang, lebar atas, lebar bawah, kedalaman $]=[3000 \mathrm{~m}, 4 \mathrm{~m}, 4 \mathrm{~m}, 3$ $\mathrm{m}]$. KCB dibuat dengan lebar $4 \mathrm{~m}$ agar bargas (perahu besi untuk angkut bibit atau TBS) dapat saling berpapasan (setiap bargas memiliki lebar $1.8 \mathrm{~m}$ ). Waktu operasional pembuatan KCB sebesar 10 jam perhari, besar kapasitas lapang $1.00 \mathrm{ha} / \mathrm{jam}$, dan waktu lapang $1.00 \mathrm{jam} / \mathrm{ha}$. Dalam Gambar 12 ditunjukkan metode dan hasil pembuatan KCB.

Central drain adalah parit yang berfugsi untuk menghubungkan field drain dengan kanal kolektor. Central drain dibuat untuk mempercepat dan memudahkan proses pelangsiran bibit pada saat proses penanaman. Parit central drain memiliki ukuran [panjang, lebar atas, lebar bawah, kedalaman $]=[3000 \mathrm{~m}, 1$ m, $1 \mathrm{~m}, 2 \mathrm{~m}]$, sebagaimana ditunjukkan dalam Gambar 13. Waktu operasional pembuatan central drain sebesar 10 jam perhari, besar kapasitas lapang $1.25 \mathrm{ha} / \mathrm{jam}$, dan waktu lapang sebesar $0.80 \mathrm{jam} / \mathrm{ha}$.

Cambering merupakankegiatan menumpuk dan meratakan tanah hasil galian CECT dan field drain menggunakan bucket excavator untuk membuat jalur tanam berbentuk cembung dengan kemiringan \pm 10 Ú dan tinggi $25 \mathrm{~cm}$ hingga 30 $\mathrm{cm}$, serta membersihkan lahan dari seresah tanaman lama. Kegiatan camberingberfungsi untuk mencegah terjadinya genangan air pada jalan rintis dan pokok tanaman karena air langsung mengalir ke CECT dan field drain serta memudahkan evakuasi TBS. Waktu operasional pembuatan central drain sebesar 10 jam perhari, besar kapasitas lapang 0.16 ha/jam, dan waktu lapang sebesar 6.25 jam/ha. Dalam Gambar 14 ditunjukkan kondisi areal lahan sebelum dan sesudah cambering.

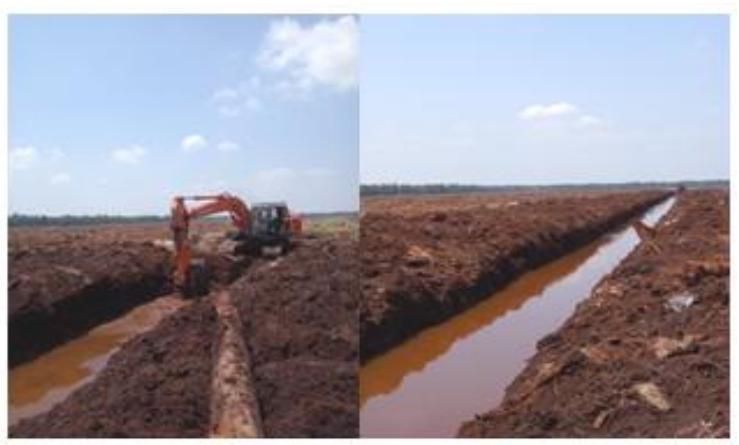

Gambar 12. Metode dan Hasil Akhir Pembuatan KCB

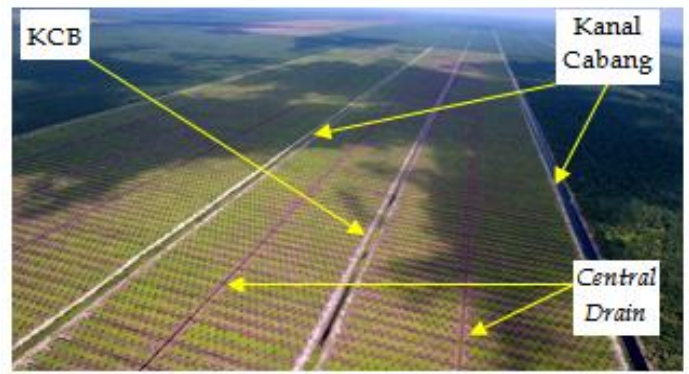

Gambar 13. Kanal Cabang, KCB, dan Central Drain
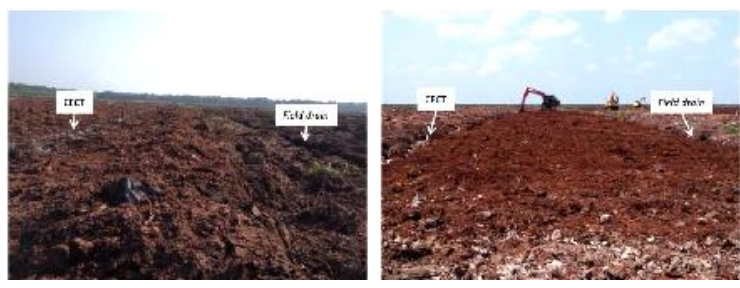

Gambar 14. Kondisi Lahan Sebelum dan Sesudah Cambering 
Compacting adalah kegiatan memadatkan jalur tanam dengan panjang $230 \mathrm{~m}$ dan lebar $5 \mathrm{~m}$ menggunakan excavator sehingga tanaman dapat tumbuh dengan baik dan lebih kokoh. Compacting dilakukan karena tanah gambut memiliki porositas tanah tinggi sehingga tidak memiliki daya cengkeram yang baik. Kegiatan compacting dilakukan setelah kegiatan cambering. Waktu operasional pembuatan central drain sebesar 10 jam perhari, besar kapasitas lapang $0.56 \mathrm{ha} / \mathrm{jam}$, dan waktu lapang sebesar $1.78 \mathrm{jam} / \mathrm{ha}$. Dalam Gambar 15 ditunjukkan kondisi areal lahan sebelum dan sesudah compacting.

Pemancangan merupakan pengaturan tata guna lahan untuk tanaman yang diatur sesuai dengan jarak tanam yang telah ditentukan sehingga didapatkan satuan per hektar (SPH) tanaman yang diinginkan. Pemancangan bertujuan untuk memberikan tanda pada titik tanam sebagai panduan operator excavator saat kegiatan holing. Di kebun gambut Mandah Estate jarak tanam yang digunakan adalah $[7.93 \mathrm{~m}-7.93 \mathrm{~m}$ $7.93 \mathrm{~m}$ ] dan jarak antar barisan $7 \mathrm{~m}$ dengan SPH tanaman 180 pokok.
Pemancangan menggunakan tali tambang yang telah dipasang simpul titik tanam yang berwarna hitam dan putih. Jarak antara simpul hitam dan putih adalah $3.96 \mathrm{~m}$, sedangkan jarak antar simpul warna hitam atau putih adalah $7.93 \mathrm{~m}$, sebagaimana ditunjukkan dalam Gambar 16. Waktu operasional pemancangan sebesar 6.5 jam perhari, besar kapasitas lapang $0.53 \mathrm{ha} / \mathrm{jam}$, dan waktu lapang sebesar $1.88 \mathrm{jam} / \mathrm{ha}$.

Holing adalah kegiatan pembuatan lubang tanam menggunakan excavator yang dipasang bucket tombi pada lengannya. Pembuatan lubang tanam menggunakan sistem hole in hole,atau lubang tanam yang dibuat di dalam lubang, yang bertujuan untuk mengantisipasi terjadinya penurunan gambut pada masa mendatang supaya akar tanaman tidak menggantung atau doyong.

Cetakan lubang atas berbentuk trapesium dengan ukuran [panjang, lebar atas] $=[100 \mathrm{~cm}, 100 \mathrm{~cm}]$, [panjang, lebar bawah] $=[55 \mathrm{~cm}, 55 \mathrm{~cm}]$, dan kedalaman $60 \mathrm{~cm}$, sebagaimana ditunjukkan dalam Gambar 17. Cetakan lubang bawah

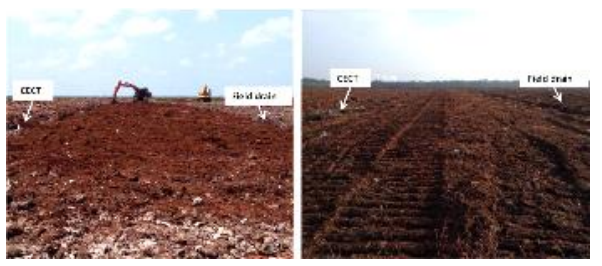

Gambar 15. Kondisi Areal Sebelum dan Sesudah Compacting

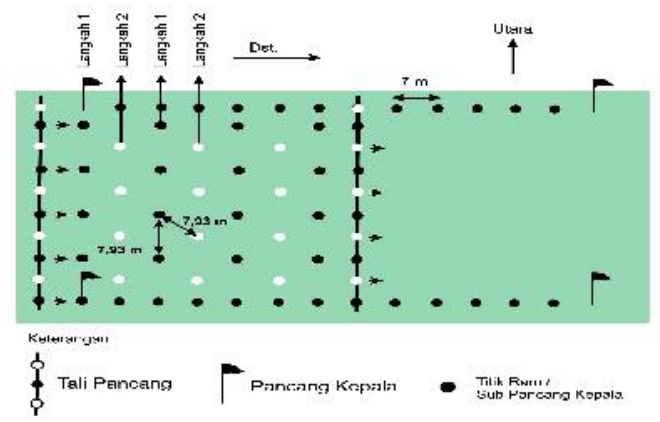

Gambar 16. Pemancangan di Areal Kebun Mandah Estate
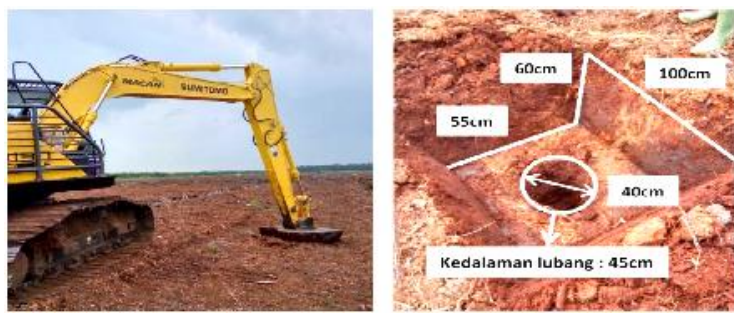

Gambar 17. Metode dan Hasil Akhir Kegiatan Holing 
berbentuk tabung yang berfungsi sebagai lubang tanam dengan ukuran diameter $40 \mathrm{~cm}$ dan kedalaman $45 \mathrm{~cm}$. Lubang tanam tidak boleh dibiarkan hingga 3 hari. Waktu operasional holing sebesar 10 jam perhari, besar kapasitas lapang $0.06 \mathrm{ha} / \mathrm{jam}$, dan waktu lapang sebesar $16.6 \mathrm{jam} / \mathrm{ha}$.

Kegiatan penanaman sawit di kebun Mandah Estate dilakukan secara manual sehari setelah kegiatan pemupukan lubang tanam. Pengambilan bibit dimuat menggunakan bargas atau ponton container (PC) yang ditarik oleh tugboat. Tugboat berbentuk segiempat dengan bagian depan mengerucut dan memiliki daya 15-23 PK dengan mesin in boat. Bargas berkapasitas muat 350 bibit sawit, sedangkan ponton container berkapasitas muat 600 bibit sawit, sebagaimana ditunjukkan dalam Gambar 18. Waktu operasional kegiatan tanam bibit sawit sebesar 6.5 jam perhari, besar kapasitas lapang $0.10 \mathrm{ha} /$ jam, dan waktu lapang sebesar 10.0 jam/ha. Penanaman LCC (legume cover crop) merupakan kegiatan menanam tanaman kacangan untuk menekan pertumbuhan gulma, mengurangi erosi oleh hujan, dan mengurangi penguapan air tanah dari lahan gambut. Kegiatan penanaman LCC terbagi menjadi 2, yaitu penggaruan alur dan penaburan benih.

Jenis kacangan yang digunakan di kebun Mandah Estate adalah Pueraria javanica (PJ) dan Colopogonium mucunoides (CM). Pemakaian bahan yang digunakan adalah PJ $3 \mathrm{~kg} / \mathrm{ha}$, CM 3 kg/ha, pupuk Rock Phosphat 6 kg/ha, dan Air bersih $30 \mathrm{ml}$. Waktu operasional kegiatan tanam LCC sebesar 6.5 jam perhari, besar kapasitas lapang $0.10 \mathrm{ha} / \mathrm{jam}$, dan waktu lapang sebesar 10.0 jam/ha. Dalam Gambar 19 ditunjukkan skema penanaman LCC.

Kegiatan peremajaan (replanting) tanaman kelapa sawit di areal lahan tanah mineral ternyata berbeda dengan di areal lahan gambut Pada Tabel 2 dan Tabel 3 ditunjukkan rekapitulasi kinerja replanting di areal lahan tanah mineral dan di areal lahan gambut.

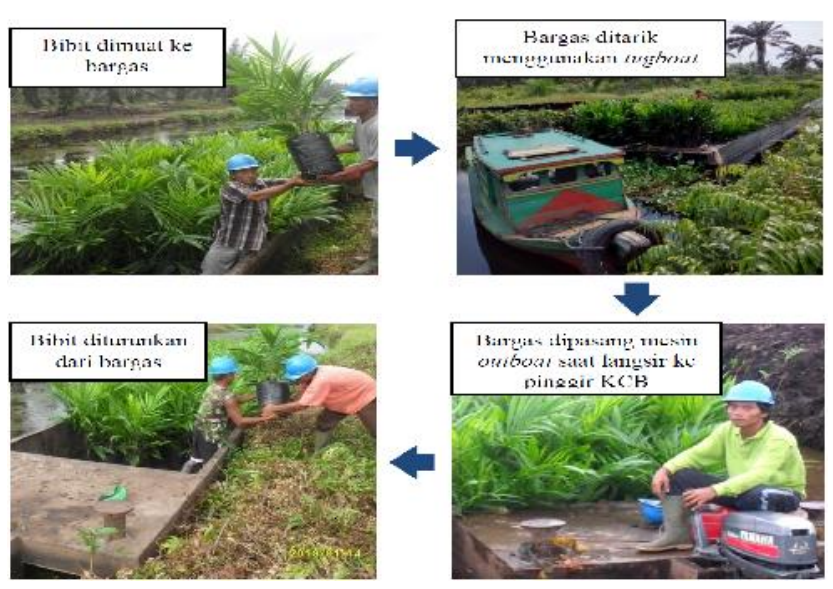

Gambar 18. Skema Transportasi Bibit di Lahan Gambut

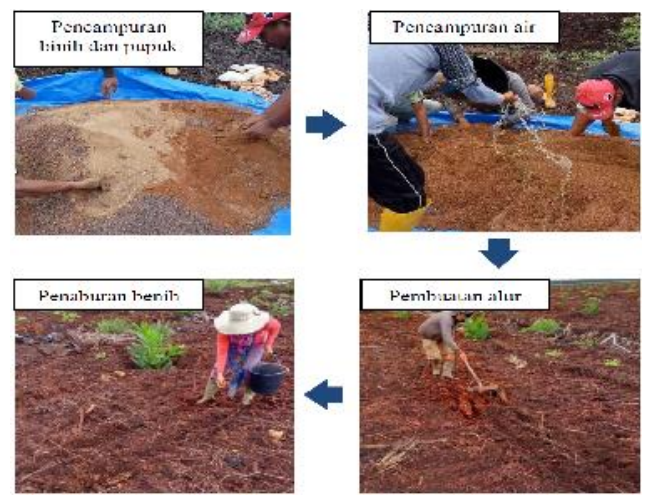

Gambar 19. Skema Penanaman LCC di Lahan Gambut 
Tabel 2. Kinerja Replanting di Areal Lahan Tanah Mineral

\begin{tabular}{clccc}
\hline \multirow{2}{*}{ No } & Kegiatan & Waktu Operasional & \multicolumn{2}{c}{ Kapasitas Lapang } \\
\cline { 4 - 5 } & & (jam) & 0.25 & (jam/ha) \\
\hline 1 & Ripping & 8 & 0.25 & 4.0 \\
2 & Plowing & 7 & 0.57 & 1.7 \\
3 & Pemancangan rumpukan & 10 & 0.05 & 20.0 \\
4 & Tumbang dan chipping & & & 1.4 \\
5 & Perbaikan drainase & 8 & 0.72 & 1.9 \\
& a) Parit primer & 8 & 0.52 & 4.3 \\
& b) Parit sekunder & 8 & 0.23 & 25.0 \\
& c) Alur & 7 & 0.04 & 33.3 \\
7 & Pemancangan tanaman & 7 & 0.03 & 8.3 \\
8 & Stek kacangan & 7 & 0.12 & 2.9 \\
9 & Penanaman kacangan & 8 & 0.35 & 7.7 \\
10 & Holing & 7 & 0.13 & 25.0 \\
11 & Pawat kacangan & 7 & 0.04 & $\mathbf{1 3 9 . 5}$ \\
\hline
\end{tabular}

Tabel 3. Hasil Kinerja Replanting di Areal Lahan Gambut

\begin{tabular}{clccc}
\hline No & \multicolumn{1}{c}{ Kegiatan } & $\begin{array}{c}\text { Waktu Operasional } \\
\text { (jam/hari) }\end{array}$ & $\begin{array}{c}\text { Kinerja } \\
\text { (ha/jam) }\end{array}$ & $\begin{array}{c}\text { Kinerja } \\
\text { (jam/ha) }\end{array}$ \\
\hline 1 & Falling, chipping, dan & 10 & 0.08 & 12.0 \\
& deboling & 10 & & \\
2 & Pembuatan CECT & 10 & 0.14 & 7.14 \\
3 & Pembuatan field drain & 10 & 0.16 & 6.25 \\
4 & Pembuatan KCB & 10 & 1.00 & 1.00 \\
5 & Pembuatan central drain & 10 & 1.25 & 0.80 \\
6 & Cambering & 10 & 0.16 & 6.25 \\
7 & Compacting & 6.5 & 0.56 & 1.78 \\
8 & Pemancangan & 10 & 0.53 & 1.88 \\
9 & Holing & 6.5 & 0.06 & 16.6 \\
10 & Penanaman kelapa sawit & 6.5 & 0.10 & 10.0 \\
11 & Penanaman LCC & $\mathbf{9 9 . 5}$ & 0.10 & 10.0 \\
\hline & Total & & & $\mathbf{7 3 . 7}$ \\
\hline
\end{tabular}

Hasil kinerja replanting di areal lahan tanah mineral (Tabel 2) dan di areal lahan gambut (Tabel 3) menunjukkan bahwa pelaksanaan serangkaian kegiatan replanting di areal lahan gambut berlangsung dalam waktu yang lebih singkat (73.7 jam/ha) dibanding di areal lahan tanah mineral (139.5 jam/ha). Salah satu penyebabnya adalah karena di areal lahan gambut tidak dilakukan kegiatan pengolahan tanah (ripping dan plowing), sebagaimana dilakukan di areal lahan tanah mineral. Disamping itu, besar kapasitas lapang di areal lahan gambut (0.06 ha/jam - 1.25 ha/jam) lebih besar dibanding di areal lahan tanah mineral (0.04 ha/ jam - $0.72 \mathrm{ha} / \mathrm{jam}$ ). Total waktu penyelesaian serangkaian kegiatan replanting di areal lahan gambut (73.7 jam/ha) lebih singkat dibanding di areal lahan tanah mineral (139.5 jam/ha).

\section{KESIMPULAN}

Kegiatan replanting di areal lahan tanah mineral meliputi pekerjaan ripping, plowing, chipping, holing hingga penanaman dengan besar kapasitas lapang (0.04 ha/jam hingga $0.72 \mathrm{ha} / \mathrm{jam})$ dan besar total waktu penyelesaian pekerjaan (waktu lapang total) sebesar $139.5 \mathrm{jam} / \mathrm{ha}$. Kegiatan replanting di areal lahan gambut meliputi pekerjaan falling, chipping, deboling, holing hingga penanaman dengan besar kapasitas lapang (0.06 ha/jam hingga $1.25 \mathrm{ha} / \mathrm{jam})$ dan besar waktu lapang total $73.7 \mathrm{jam} / \mathrm{ha}$.

\section{UCAPAN TERIMA KASIH}

Ucapan terimakasih disampaikan kepada PT Socfindo, Kebun Aek Loba, Kabupaten Asahan, 
Provinsi Sumatera Utara dan PT Bhumireksa Nusa Sejati, Kebun Mandah Estate, Desa Bente, Kecamatan Mandah, Kabupaten Indragiri Hilir, Provinsi Riau yang telah memfasilitasi kegiatan pengamatan mengenai teknik proses peremajaan (replanting) tanaman kelapa sawit Tak lupa pula disampaikan ucapan terimakasih kepada PERTETA Pusat dan PERTETA Cabang Yogyakarta yang memfasilitasi kegiatan Seminar Nasional PERTETA 2018.

\section{DAFTAR PUSTAKA}

[BPDP Sawit] Badan Pengelola Dana Perkebunan Kelapa Sawit 2017. Program Peremajaan Perkebunan Kelapa Sawit Rakyat. Pusat Penelitian Kelapa Sawit (IOPRI) [Internet]. [diunduh 2017 Nov 05]. Tersedia pada: http://www.iopri.org/

[BPS] Badan Pusat Statistik. 2017. Produksi Tanaman Perkebunan Menurut Provinsi dan Jenis Tanaman Indonesia (2010 2015). [internet]. [diunduh pada 2017
Oktober 03]. Tersedia pada : https:// www.bps.go.id/linkTableDinamis/view/ id/839

Fauzi, Y., Widiyastuti, Y.E., Satyawibawa, I., Paeru, R.H. 2012. Kelapa Sawit. Jakarta (ID): Penebar Swadaya

Pahan, I. 2008. Panduan Lengkap Kelapa Sawit: Manajemen Agribisnis dari Hulu hingga Hilir. Jakarta (ID): Penebar Swadaya

Risza, S. 1994. Kelapa Sawit Upaya Peningkatan Produktivitas. Yogyakarta (ID): Kanisius

Siswadi. 2016. Panduan Praktis Agribisnis Kelapa Sawit Rakyat Berwawasan Lingkungan (dengan Potensi Produksi 42 Ton/Ha/ Tahun). Yogyakarta (ID): Deepublish

Sunarko. 2014. Budidaya Kelapa Sawit di Berbagai Jenis Lahan. Jakarta (ID): AgroMedia Pustaka 